\title{
ESTUDO DO EFEITO DE DRENO DE PENROSE NA CAVIDADE PERITONEAL DE RATOS
}

\section{THE EFFECT OF A PENROSE'S DRAIN IN THE PERITONEAL CAVITY OF RATS}

\author{
Gutemberg Fernandes de Araújo, TCBC-MA ${ }^{1}$ \\ Orlando José dos Santos, ACBC-MA ${ }^{2}$ \\ Manoel Francisco da Silva Santos, ACBC-MA ${ }^{2}$ \\ Ricardo Maurício Batista Feitosa Cuba, ACBC-MA ${ }^{3}$ \\ Janayna Vidal Flores Freitas ${ }^{4}$
}

\begin{abstract}
RESUMO: Objetivo: Estudar o efeito do dreno de Penrose na cavidade peritoneal de ratos. Método: Foram selecionados 30 ratos Wistar do mesmo sexo,divididos em três grupos de 10 animais, todos submetidos à introdução e fixação de dreno (Penrose) na cavidade peritoneal. Os períodos de observação , após os quais os animais foram mortos para estudo foram: grupo I - 24 horas; grupo II - sete dias; grupo III - 14 dias. Resultados: Foi observada a formação de aderências nos animais dos três grupos, sendo que no grupo I, as aderências foram tênues em seis animais, moderadas em dois e intensas em dois. No grupo II, foi observada aderência tênue em um animal, moderada em cinco e intensas em quatro. Conclusões: A presença de dreno de Penrose na cavidade peritoneal de ratos induz à formação de aderências.
\end{abstract}

Descritores: Drenagem; Cavidade abdominal; Ratos wistar.

\section{INTRODUÇÃO}

O peritônio é uma membrana serosa que reveste a cavidade peritoneal. Tem por função proteger os órgãos que envolve contra atritos, bem como agir na defesa da cavidade contra traumas, processos inflamatórios ou infecciosos.

A drenagem peritoneal é controversa e induz a freqüentes discussões sobre sua real necessidade e dos efeitos deletérios do dreno na cavidade. É mais comumente utilizada nas seguintes situações: (a) para drenar fluídos localizados que estejam presentes no momento da operação; (b) para drenar a cavidade peritoneal na peritonite difusa e (c) profilaticamente, com a finalidade de evidenciar os fluídos que apareçam na cavidade peritoneal logo após a operação ${ }^{1}$. Entretanto, tem sido enfatizado que a drenagem adequada de toda a cavidade peritoneal é física e fisiologicamente impossível. ${ }^{2}$
Embora a drenagem da cavidade peritoneal seja necessária em grande número de casos, o dreno funciona como um corpo estranho para o organismo, estando, portanto, diretamente relacionado com a resposta peritoneal subseqüente ${ }^{2}$.

Estudos demonstraram que a presença de drenos na cavidade peritoneal aumenta a incidência de aderências, obstruções, trajetos fistulosos e acentua a reação inflamatória local colaborando para um atraso no processo de cicatrização do período póscirúrgico $^{3,4}$. Baseado nessas informações, nos propusemos a investigar o efeito do dreno de Penrose na cavidade peritoneal de ratos.

\section{MÉTODO}

Foram utilizados 30 ratos wistar (Ratus norvegicus albinus), com quatro meses de idade, fê-

1. Professor Adjunto-Doutor de Clínica Cirúrgica I da Universidade Federal do Maranhão - UFMA.

2. Cirurgião Geral do Hospital Universitário da UFMA.

3. Cirurgião Geral do Hospital do Servidor Público Estadual.

4. Aluna do Sexto Ano do Curso de Medicina da UFMA.

Recebido em 08/10/2002

Aceito para publicação em 29/04/2003

Trabalho realizado na Universidade Federal do Maranhão. 
meas, pesando aproximadamente $250 \mathrm{~g}$, provenientes do biotério central da Universidade Federal do Maranhão. A amostra foi dividida aleatoriamente em três grupos contendo 10 animais cada. Todos os animais foram submetidos a procedimentos idênticos, diferindo apenas quanto ao período de observação. Os ratos foram mantidos em gaiolas de plástico com cobertura em aço inoxidável, forradas com serragem, com ração comercial e água à vontade, sendo um número de cinco animais por gaiola. A anestesia dos animais foi feita por meio de sistema semi-fechado por inalação de éter sulfúrico e como parâmetro anestésico a ausência de dor e reflexos interdigitais. O plano anestésico foi mantido por inalação intermitente através de aparelho montado com vaporização artesanal de éter sulfúrico. Foram utilizados drenos de Penrose n. $^{\circ}$ 01, cortados ao meio, estéreis e de tamanhos uniformes $(2 \mathrm{~cm}$ de comprimento e $1 \mathrm{~cm}$ de largura).

Os procedimentos operatórios seguiram os princípios da técnica asséptica. Todos os animais foram submetidos à incisão longitudinal mediana imediatamente abaixo do apêndice xifóide com $3 \mathrm{~cm}$ de extensão. Após hemostasia por compressão procedeu-se à introdução do dreno de Penrose na cavidade peritoneal de modo que a extremidade proximal do dreno foi posicionada a nível sub-hepático (Figura 1) e a outra extremidade fixada no tecido subcutâneo com fio monofilamentar 5.0 agulhado (Figura 2). Para uniformizar o local de fixação do dreno, marcou-se inicialmente um ponto $2 \mathrm{~cm}$ abaixo do apêndice xifóide e a partir deste ponto traçou-se uma linha perpendicular à linha média para a direita marcando-se o ponto de fixação do dreno a $2,5 \mathrm{~cm}$ do ponto $\mathrm{A}$.

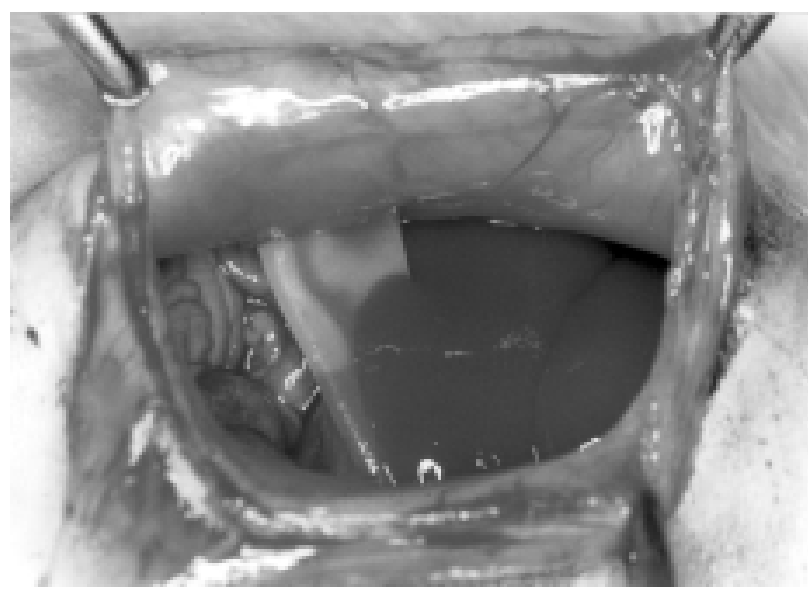

Figura 1 - Dreno posicionado a nível sub-hepático.
A síntese da parede anterior foi realizada em dois planos, o primeiro interessando conjuntamente peritônio parietal e estrato músculo-aponeurótico , com sutura por pontos separados com fio categute simples 3.0 agulhado. $\mathrm{O}$ segundo plano compreendeu pele $\mathrm{e}$ tela subcutânea com pontos separados com fio de polipropileno 5.0.

Os animais foram aquecidos e embalados no período pós-operatório imediato e mantidos em gaiolas nas mesmas condições do pré-operatório. Foram acompanhados diariamente com avaliação do estado geral e da ferida operatória. Os animais foram mortos por inalação de dose letal de éter sulfúrico. A morte dos animais do Grupo I foi realizada com 24 horas de pós-operatório, a do grupo II com sete dias e a do grupo III com 14 dias de pós-operatório. Foi incisada a parede abdominal ventral em arco, com concavidade voltada para direita. Após rebatê-la lateralmente foi feita avaliação macroscópica e registro fotográfico das alterações encontradas. As aderências, caso existissem, foram classificadas como: tênues, quando ocorriam aderências com o omento e/ou parede abdominal, moderadas, quando além do omento havia aderência com alças intestinais, e intensas, quando constituíam um bloco inflamatório com todas as estruturas regionais ${ }^{5}$.

Os resultados obtidos foram submetidos a análise estatística por meio do teste $X^{2}$. Diferenças foram consideradas significantes quando $\mathrm{p}<0.05$.

\section{RESULTADOS}

Não houve mortalidade entre os animais, nem intercorrências clínicas durante a observação

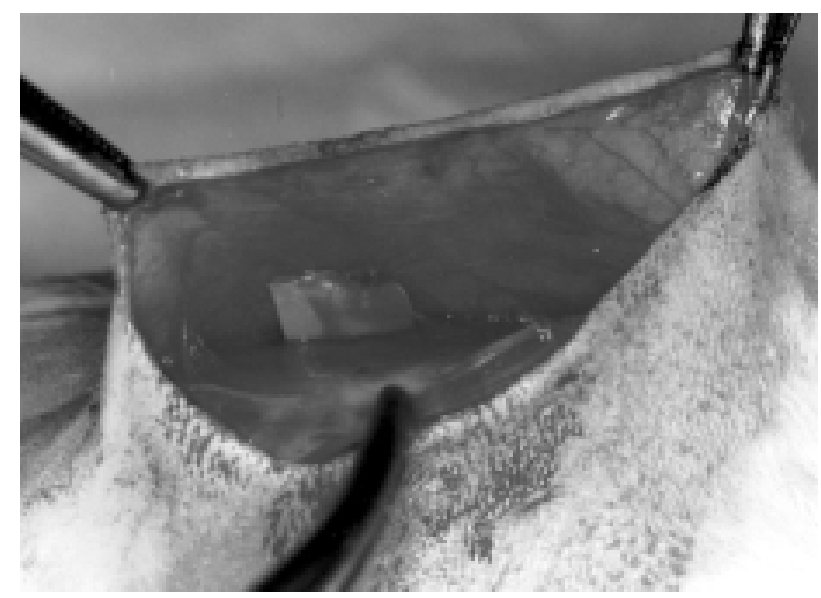

Figura 2 - Fixação do dreno no tecido subcutâneo. 
Tabela I - Avaliação da intensidade de aderências entre o dreno de Penrose e estruturas intra-peritoneais nos grupos I, II e III.

\begin{tabular}{ccccc}
\hline Grupo/Aderência & Tênue & Moderada & Intensa & Ausente \\
\hline I & $6 / 10$ & $2 / 10$ & $0 / 10$ & $2 / 10$ \\
II & $1 / 10$ & $5 / 10$ & $3 / 10$ & $1 / 10$ \\
III & $0 / 10$ & $6 / 10$ & $4 / 10$ & $0 / 10$ \\
\hline
\end{tabular}

diária. Observou-se abaulamento no local de colocação do dreno em dois animais pertencentes ao grupo III. Foi observado abscesso no local de colocação do dreno em um animal pertencente ao grupo III. Retrações, fístulas, secreções purulentas ou sanguinolentas não foram observadas dentro da cavidade peritoneal. Houve formação de aderências nos animais dos três grupos estudados (Tabela I).

Nos animais do grupo I, as aderências foram tênues em seis animais, moderadas em dois e não se observou formação de aderências em dois animais. Nos animais do grupo II houve formação de aderências tênues em um animal, moderadas em cinco, intensas em três animais e em um não se observou formação de aderências. Nos animais do grupo III as aderências foram moderadas em seis animais e intensas em quatro (Figura 3 ).

Não houve diferença estatisticamente significante entre os grupos I, II e III, quando comparamos formação de aderências/ausência de aderência com o tempo de permanência do dreno na cavidade (Tabelas II e III).

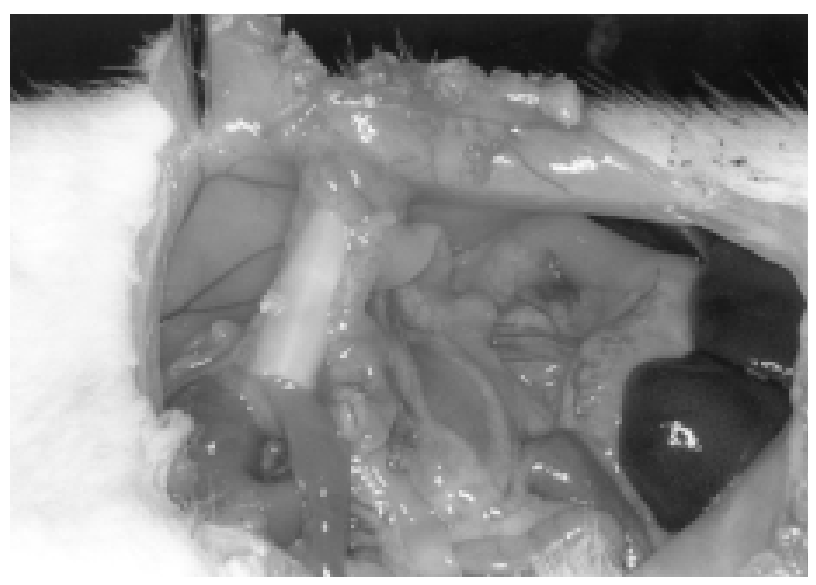

Figura 3 - Aderências intensas entre o dreno e estruturas regionais constituindo bloco inflamatório em animal do grupo III.
Tabela II - Avaliação da formação de aderências ao dreno de Penrose X tempo de observação.

\begin{tabular}{lcc}
\hline Tempo & Aderência & Total \\
\hline 1 dia & 8 & $29.6 \%$ \\
7 dias & 9 & $33.3 \%$ \\
14 dias & 10 & $37.0 \%$ \\
Total & 27 & $99.9 \%$ \\
\hline
\end{tabular}

$p=1.0>0.05$

Tabela III - Avaliação da não formação de aderências ao dreno de Penrose $X$ tempo de observação.

\begin{tabular}{lcc}
\hline Tempo & Ausência de aderência & Total \\
\hline 1 dia & 2 & $66.7 \%$ \\
7 dias & 1 & $33.3 \%$ \\
Total & 3 & $100 \%$ \\
\hline
\end{tabular}

$p=1.0>0.05$

\section{DISCUSSÃO}

O uso de drenos que data desde os tempos de Hipócrates, tem resistido ao teste do tempo na prática cirúrgica ${ }^{6}$. Quando existem coleções de sangue ou fluído infectado, a necessidade de drenagem não pode ser discutida. Entretanto, os métodos de drenagem e o tempo de duração do dreno no lugar, e o bom senso de drenagem profilática, são admitidos ainda como pontos de controvérsia ${ }^{5}$. Embora as indicações de drenagem cirúrgica sejam bem conhecidas, sabese que a presença de um dreno na cavidade peritoneal pode induzir a efeitos deletérios.

É sabido que a presença de um dreno de Penrose aumenta a formação de aderências na cavi- 
dade peritoneal ${ }^{5}$. O presente estudo ratifica estas observações uma vez que nos três grupos analisados observou-se formação de aderências.

As aderências formam-se ao redor de qualquer corpo estranho e suas extensões e densidades dependem do grau e duração da irritação desse corpo. Quanto maior e mais prolongada a irritação, mais intensa é a reação e mais firme serão as aderências ${ }^{4}$. Neste estudo observou-se que as aderências foram em sua maioria tênues no grupo I (6/10), no qual o tempo de observação foi de apenas 24 horas, enquanto nos grupos II e III, em que o período de observação foi maior, sete e 14 dias respectivamente, houve maior número de aderências moderadas e intensas. Ou seja, a intensidade foi progressiva e proporcional ao período de observação.

Utilizou-se fio absorvível na síntese do estrato músculo-aponeurótico e peritônio parietal com o intuito de minimizar uma reação inflamatória crônica do tipo corpo estranho, que poderia interferir no processo cicatricial e falsear os achados no final do estudo. A escolha da incisão longitudinal mediana deveuse ao fato de representar acesso fácil à cavidade e permitir a realização dos procedimentos necessários de maneira adequada. A fixação do dreno no tecido celular subcutâneo foi realizada com o intuito de evitar o contato do meio externo com a cavidade peritoneal. $\mathrm{O}$ dreno de látex (Penrose) foi utilizado por ser um dos drenos mais comumente usados na prática cirúrgica ${ }^{7}$.

As aderências, quase sempre ao redor do dreno, aparecem com menos de 24 horas $^{4}$. Nosso estudo ratifica esta constatação, pois no grupo I (com tempo de observação de 24 horas) houve formação de aderência em oito dos 10 animais deste grupo.

Concluiu-se, portanto, que o dreno de látex na cavidade peritoneal de ratos provoca formação de aderências ao seu redor.

\begin{abstract}
Background: To study the effect of a Penrose's drain in the peritoneal cavity of 30 Wistar rats divided in three groups, each of them with 10 rats. Methods: Thirty Wistar rats of the same sex were selected. They were submitted to the placement and fixation of the Penrose drain in the peritoneal cavity. The groups diferred among themselves only in terms of the euthanasia time considered: group I-euthanasia after 24 hours; group II - euthanasia after seven days; group III - euthanasia after 14 days. Results: The formation of adherences were observed in all three groups of animals. In group I weak adherences were observed in six animals, moderate ones in two rats and strong adherences were observed in two rats. In group II weak adherences were observed in one animal, moderate ones in five rats and strong adherences in three animals. In group III, moderate adherences were present in six animals and strong ones were observed in four rats. Conclusions: The presence of the Penrose's drain in the peritoneal cavity of rats leads to the formation of adherences.
\end{abstract}

Key Words: Drainage; Abdominal cavity; Rats, wistar.

\section{REFERÊNCIAS}

1. Schuler C, Hartmann MJ, Souza HP - Drenagem da cavidade abdominal: uma visão atual. Acta Med (Porto Alegre), 1998, (1):35-43.

2. Dougherty SH, Simmons RL - The biology and practice of surgical drains. Part I. Curr Probl Surg, 1992, 29(8):559623.

3. Hanna EA - Efficiency of peritoneal drainage. Surg Gynecol Obstet, 1970, 131(5):983-985.

4. Agrama HM, Blackwood JM, Brown CS, et al. Functional longevity of intraperitoneal drains: an experimental evaluation. Am J Surg, 1976, 132(3): $418-421$
5. Czeczko NG, Tebet JR, Muniz JC, et al. - Estudo experimental da presença do dreno de penrose ao nível de anastomose colocólica com e sem peritonite. Acta Cir Bras, 1992, 7(4):147-150.

6. Yates JL - An experimental study of the local effects peritoneal drainage. Surg Gynecol Obstet, 1905, 1:473-492.

7. Maull KI - Securing soft latex drains. A practical method. Am J Surg, 1983, 145(3):405

Endereço para Correspondência:

Gutemberg Fernandes de Araújo

Rua Miragem do Sol 27/601.Res. Broadway

Renascença II. São Luís - Maranhão - CEP:65070.760

E-mail: gutembergaraujo@elo.com.br 